\title{
Spinal column shortening for tethered cord syndrome associated with myelomeningocele, lumbosacral lipoma, and lipomyelomeningocele in children and young adults
}

\author{
Guillermo Aldave, MD, PhD, ${ }^{1}$ Daniel Hansen, MD, ${ }^{1}$ Steven W. Hwang, MD, ${ }^{2}$ Amee Moreno, NP, \\ Valentina Briceño, RN, ${ }^{1}$ and Andrew Jea, MD ${ }^{1,3}$ \\ 1Division of Pediatric Neurosurgery, Texas Children's Hospital, Department of Neurosurgery, Baylor College of Medicine, \\ Houston, Texas; ${ }^{2}$ Shriners Hospitals for Children, Philadelphia, Pennsylvania; and ${ }^{3}$ Section of Pediatric Neurosurgery, Riley \\ Hospital for Children, Department of Neurosurgery, Indiana University School of Medicine, Goodman Campbell Brain and Spine, \\ Indianapolis, Indiana
}

OBJECTIVE Tethered cord syndrome is the clinical manifestation of an abnormal stretch on the spinal cord, presumably causing mechanical injury, a compromised blood supply, and altered spinal cord metabolism. Tethered cord release is the standard treatment for tethered cord syndrome. However, direct untethering of the spinal cord carries potential risks, such as new neurological deficits from spinal cord injury, a CSF leak from opening the dura, and retethering of the spinal cord from normal scar formation after surgery. To avoid these risks, the authors applied spinal column shortening to children and transitional adults with primary and secondary tethered cord syndrome and report treatment outcomes. The authors' aim with this study was to determine the safety and efficacy of spinal column shortening for tethered cord syndrome by analyzing their experience with this surgical technique.

METHODS The authors retrospectively reviewed the demographic and procedural data of children and young adults who had undergone spinal column shortening for primary or secondary tethered cord syndrome.

RESULTS Seven patients with tethered cord syndrome caused by myelomeningocele, lipomyelomeningocele, and transitional spinal lipoma were treated with spinal column shortening. One patient with less than 24 months of follow-up was excluded from further analysis. There were 3 males and 4 females; the average age at the time was surgery was 16 years (range 8-30 years). Clinical presentations for our patients included pain (in 5 patients), weakness (in 4 patients), and bowel/bladder dysfunction (in 4 patients). Spinal column osteotomy was most commonly performed at the L-1 level, with fusion between T-12 and L-2 using a pedicle screw-rod construct. Pedicle subtraction osteotomy was performed in 6 patients, and vertebral column resection was performed in 1 patient. The average follow-up period was 31 months (range 26-37 months). Computed tomography-based radiographic outcomes showed solid fusion and no instrumentation failure in all cases by the most recent follow-up. Five of 7 patients (71\%) reported improvement in preoperative symptoms during the follow-up period. The mean differences in initial and most recent Scoliosis Research Society Outcomes Questionnaire and Oswestry Disability Index scores were 0.26 and $-13 \%$, respectively; minimum clinically important difference in SRS-22 and ODI were assumed to be $0.4 \%$ and $-12.8 \%$, respectively.

CONCLUSIONS Spinal column shortening seems to represent a safe and efficacious alternative to traditional untethering of the spinal cord for tethered cord syndrome.

https://thejns.org/doi/abs/10.3171/2017.1.PEDS16533

KEYWORDS lipomyelomeningocele; myelomeningocele; shortening; spina bifida; spinal column; tethered cord syndrome; spine; congenital

ABBREVIATIONS EBL = estimated blood loss; MCID = minimum clinically important difference; ODI = Oswestry Disability Index; PSO = pedicle subtraction osteotomy; SRS-22 = Scoliosis Research Society Outcomes Questionnaire.

SUBMITTED September 15, 2016. ACCEPTED January 19, 2017.

INCLUDE WHEN CITING Published online March 31, 2017; DOI: 10.3171/2017.1.PEDS16533. 
$\mathrm{T}$ Iethered cord syndrome is a clinical diagnosis with a constellation of signs and symptoms, including back and leg pain, other sensory changes, leg weakness, foot deformity, scoliosis, and bowel and bladder dysfunction. ${ }^{9,22,23,26,27,30}$ The pathophysiology of tethered cord syndrome has been hypothesized to be an abnormal stretch of the spinal cord, leading to altered blood flow and hypoxic stress and subsequent worsened mitochondrial oxidative metabolism and electrophysiological insult. It is assumed that prolonged neuronal dysfunction may lead to structural damage to neuronal perikarya and axons. ${ }^{33}$

Initial treatment for tethered cord syndrome may involve an untethering procedure, which consists of the surgical release of abnormal attachments between the neural elements, adjacent structures, and scar tissue, releasing excessive tension on the spinal cord. ${ }^{20,30}$ While untethering is a well-accepted treatment option for tethered cord syndrome, ${ }^{5,19,22}$ recurrent tethering from scar formation, a natural reaction to surgery, is a significant risk. Reported rates of secondary tethered cord syndrome following repair of myelomeningoceles have been estimated to be between $3 \%$ and 32\%; the incidence of recurrent tethered cord syndrome after surgery for lipomyelomeningocele has been reported to be as high as $40 \% .^{30}$

Surgical untethering may lead to a vicious cycle of repeated untethering procedures during a patient's lifetime. With multiple untethering procedures, dense arachnoiditis encountered during dissection may increase the procedural risk of new neurological deficits from damage to the spinal cord and nerve roots. Meanwhile, the ability to adequately untether the spinal cord decreases with each untethering attempt. Hence, the law of diminishing returns for repeated untethering takes effect (i.e., low chance of accomplishing the surgical goal of untethering, and high risk of neurological injury). ${ }^{18,24,30}$ Multiple surgeries also increase the risk of wound dehiscence, surgical site infection, and CSF leak. ${ }^{24}$

Due to the limitations and technical challenges of traditional untethering, new paradigms for treating tethered cord syndrome have been proposed to address its shortcomings. Spinal column shortening avoids the problem of intradural manipulation of critical neural elements and $\mathrm{CSF}$ and retethering. It reduces the distance that the spinal cord is stretched, thereby decreasing tension at the point of tethering ${ }^{2}$ with satisfactory outcomes. ${ }^{13,14,17,28,25}$ In this study, we report our experience with the spinal column shortening technique and its associated outcomes in 7 patients.

\section{Methods \\ Patient Population}

We reviewed the records obtained in pediatric patients (age $<18$ years) and adults (age $\geq 18$ years) with pediatric spinal disorders, such as spinal dysraphism (transitional patients, i.e., children with spinal disorders who become adults and have chronic medical problems due to their disorder), who underwent spinal column shortening for tethered cord syndrome at Texas Children's Hospital. Only patients with at least 24 months of follow-up were included in the analysis. This retrospective study/chart review received approval from the Baylor College of Medicine institutional review board.

\section{Surgical Indications}

All patients in our series had progressive signs and symptoms of tethered cord syndrome, and all had a history of myelomeningocele or spinal lipoma. These signs and symptoms included back and leg pain, leg or foot weakness, and/or bowel and bladder dysfunction. Furthermore, all patients underwent urology evaluation with formal urodynamics to document bladder function prior to surgery.

Preoperative MRI performed in each patient showed a low-lying conus, syringomyelia, or a terminal or transitional type of lipoma by the Chapman classification (in the case of a diagnosis of spinal lipoma). ${ }^{4}$

A traditional untethering approach and spinal column shortening were offered to the patient and caregiver(s). Risks and benefits of each treatment option were discussed thoroughly, including the fact that there are no published reports of long-term outcomes for the spinal column shortening procedure, especially in skeletally immature children. The decision for spinal column shortening was made in conjunction with the wishes and desires of the patient and caregiver(s).

Each case was then discussed in our indications conference. The management plan was deemed acceptable by a panel of 5 other board-certified pediatric neurosurgeons before moving forward with surgery.

\section{Surgical Procedure}

Spinal column shortening was performed as previously described. ${ }^{13,18}$ The shortening procedure was centered at the level of L-1 in all patients, with the exception of 2 patients. In most cases, we performed pedicle subtraction osteotomy (PSO) (6 patients) rather than vertebral column resection, as used by Hsieh et al. ${ }^{13}$ We hypothesized that, by introducing lordosis with a PSO, the spinal cord would migrate dorsally, away from the dorsum of the vertebral body, particularly in cases of exaggerated kyphosis. The PSO performed in a standard manner at L-1 is described briefly below.

Laminectomies from $\mathrm{T}-12$ to $\mathrm{L}-2$ were performed. Pedicle screws were placed bilaterally at T-12 and L-2. The pedicles at L-1 were then isolated after resection of T12-L1 and L1-2 facet joints, articular processes, pars interarticularis, and transverse processes. Using a combination of a Leksell rongeur and a high-speed air-powered drill, the pedicle on one side was resected down to its confluence with the posterior cortex of the vertebral body. The rostral portion of the L-1 vertebral body was drilled away on one side, with a rod coupling the pedicle screws on the opposite side, which prevented closure of the 1.5 $\mathrm{cm}$ osteotomy gap. The bony superior endplate of L-1 was not violated. The anterior cortex of the vertebral body was thinned but preserved.

The same steps were repeated on the other side with a rod assembled on the opposite side for resection of the remaining portion of the rostral portion of L-1. The posterior cortex in front of the thecal sac and spinal cord/conus medullaris/cauda equina was thinned to the consistency of 
an eggshell, and it was removed piecemeal with a downpushing curette and Kerrison rongeurs, along with the posterior longitudinal ligament. The osteotomy defect, filled with a small dose of bone morphogenetic protein, was gradually closed by compression applied to the pedicle screws at T-12 and L-2 using the rods as guides to obtain bone-on-bone contact. Bone morphogenetic protein and morcellized local autograft and allograft were also placed over the exposed bony elements from T-12 to L-2 to complete the posterior fusion. Bone morphogenetic protein to facilitate arthrodesis was used in an "off-label" manner in this series of pediatric and adult patients. We recognize that use of bone morphogenetic protein in children is controversial. A full discussion of the merits and faults of recombinant human bone morphogenetic protein-2 use in children is beyond the scope of this study. However, we do cover this topic in a series of previously published studies. ${ }^{10,21,31,32}$ Furthermore, written informed consent was obtained from the patient or legal guardian for off-label use of bone morphogenetic protein as described above.

Somatosensory evoked potentials and transcranial motor evoked potentials were used throughout the procedure. We noted any changes in intraoperative neurophysiological parameters.

\section{Clinical Evaluation}

The medical and operative records, radiographs, CT scans, and MR images were retrospectively reviewed. Gait ability, pain and sensory changes, arm and leg strength, bowel and bladder function, and patient-reported outcomes were assessed at each clinic visit: preoperatively, 2 weeks after surgery, 3 months after surgery, 6 months after surgery, and then annually. We used the Scoliosis Research Society Outcomes Questionnaire (SRS-22) ${ }^{1-3}$ and Oswestry Disability Index (ODI) ${ }^{8}$ as our patient-reported outcomes. Neither tool has been validated for the purposes of evaluating outcomes in the spinal dysraphism or tethered cord patient population. Moreover, SRS-22 has been validated for score distribution and internal consistency in a population of patients with spinal deformity who range in age from 7 to 78 years; however, the ODI has not been validated as a health-related quality of life instrument for 8-year-old children. To the best of our knowledge, there are no disease-specific patient-reported outcomes specifically designed for our study cohort.

SRS-22 is used to measure how a spinal deformity, such as scoliosis, is affecting a patient's overall life before and after surgery. The questionnaire covers 5 domains (pain, function, self-image, mental health, and overall satisfaction) of a patient's life. A score of 1 on the SRS-22 represents the worst response, while a score of 5 is the best. The minimum clinically important difference (MCID) for SRS-22 is 0.4..$^{7}$ The ODI is used to measure how lumbar spine disease and associated pain affect a patient's life. It covers 10 aspects (pain, personal care, lifting, walking, sitting, standing, sleeping, sex life, social life, and travel) of a patient's life. An ODI score of $0 \%-20 \%$ represents minimal disability; $21 \%-40 \%$ moderate disability; $41 \%-60 \%$ severe disability; 61\%-80\% crippled; and $81 \%-100 \%$ bedbound. The MCID for ODI is $-12.8 \% .^{6}$

\section{Radiographic Evaluation}

At 12 months after surgery, assessment of fusion was performed based on CT findings of the spinal region of interest. Full-spine upright radiographs were obtained to analyze sagittal alignment. An MRI study was obtained as needed only in cases of new complaints or concerns, such as pain or neurological deficit after surgery.

\section{Results \\ Clinical Evaluation}

The study group comprised 3 males and 4 females with primary or secondary tethered cord syndrome due to myelomeningocele ( 3 patients), lipomyelomeningocele (3 patients), or transitional spinal lipoma (1 patient). The mean age at the time of surgery was 16 years (range 8-30 years). The average postoperative follow-up period was 31 months (range 26-37 months).

Clinical presentation included back pain (3 patients); leg complaints, including weakness pain, numbness, and vasomotor instability (6 patients); changes in bowel and bladder function (4 patients); and an enlarging spinal cord syrinx associated with hand weakness (1 patient). Six patients had undergone initial repair of a form of spinal dysraphism, and 1 patient had never undergone previous surgery for spinal dysraphism repair. One patient had not undergone a prior untethering procedure, and 2 patients had undergone 3 prior untethering procedures. Untethering procedures were defined as surgeries subsequent to the initial repair of the spinal dysraphism.

The mean operative time was 6 hours and 40 minutes (range 4 hours and 30 minutes to 8 hours and 44 minutes). The average estimated blood loss (EBL) was $587 \mathrm{ml}$ (range 250-900 ml). There were no intraoperative complications or cases of postoperative wound infection or CSF leakage. The mean hospital stay was 5 days (range 4-6 days). One patient experienced a catastrophic failure of her spinal instrumentation and proximal junctional kyphosis at 3 months after surgery, which necessitated revision surgery with extension of her spinal instrumentation and fusion (Fig. 1).

During the postoperative period, 5 patients reported improvement in their preoperative symptoms. Two patients reported no change or a worsening of their preoperative symptoms. The time course of changes in SRS-22 and ODI for 6 and 5 patients, respectively, is presented in Fig. 2. The mean overall SRS-22 score at last follow-up was 3.31 (range 2-4.5). The mean difference between the final and initial SRS-22 scores was 0.26 (range -0.59 to 1.05 ), falling short of an MCID of 0.4. The mean overall ODI score was 30\% (range 3\%-54\%). The mean difference between final and initial ODI scores was $-13 \%$ (range $2 \%$ to $-32 \%$ ) surpassing the MCID of $-12.8 \%$.

Patient demographics and clinical and operative data are summarized in Table 1.

\section{Imaging Evaluation}

All patients demonstrated solid arthrodesis based on CT findings at 12 months after surgery. The mean sagittal alignment before surgery was $4^{\circ}$ of kyphosis before surgery (range $-1^{\circ}$ to $10^{\circ}$ ); the mean kyphosis at the most 

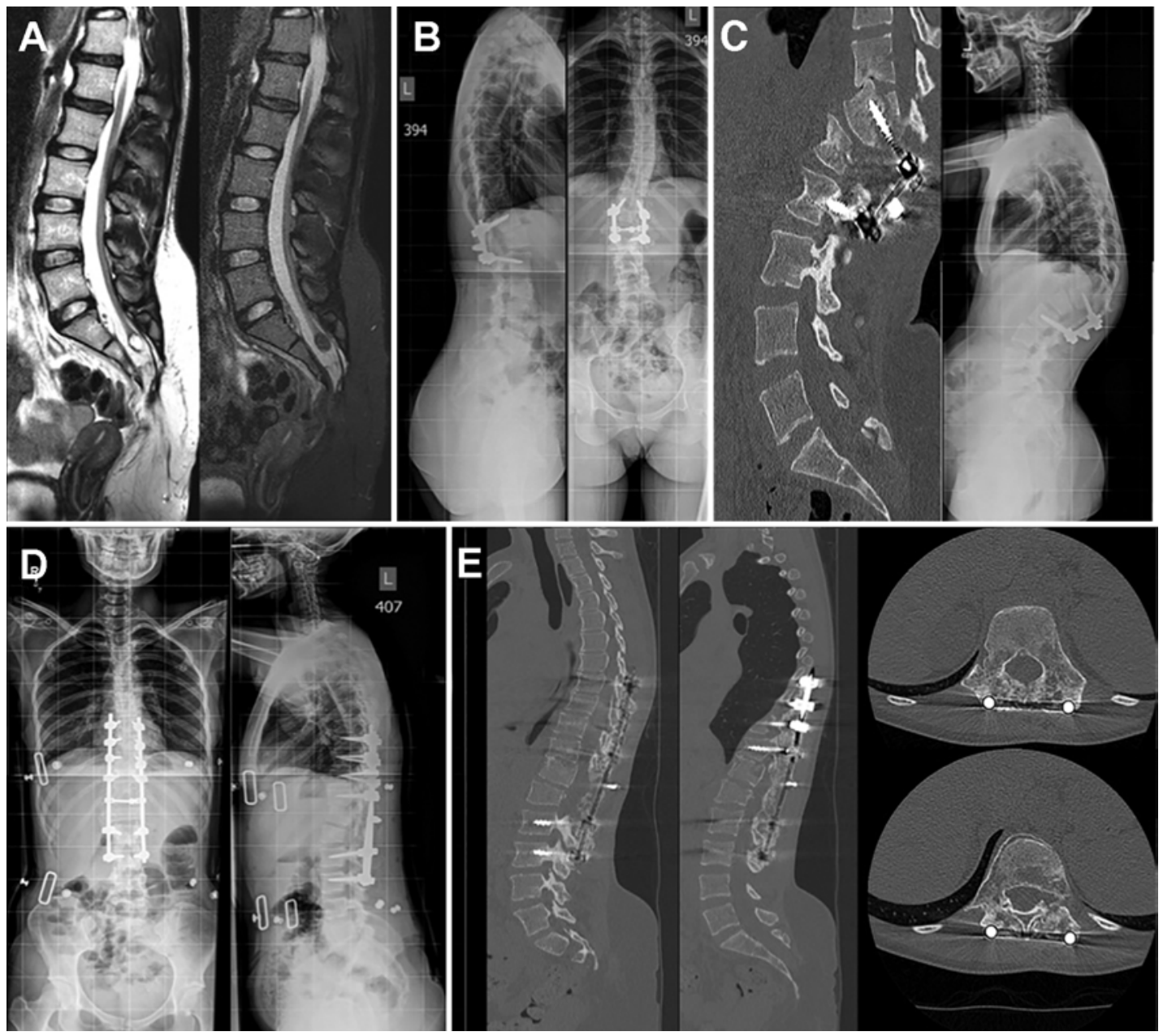

FIG. 1. Patient 4. A 23-year-old woman presented to the clinic with a history of lipomyelomeningocele repair and complaints of back and leg pain. A: Preoperative sagittal T2-weighted MR image (left) and fat-suppressed T2-weighted MR image (right) showing a "radiographically" tethered spinal cord. The patient also reported intermittent autonomic instability of her lower extremities, saying that her legs and feet "turn purple." Urodynamic testing demonstrated worsened bladder function compared with baseline. The patient did not undergo any prior untethering procedures for secondary tethered cord syndrome. She underwent an L-1 PSO and T12-L2 posterior instrumented fusion. The EBL was $500 \mathrm{ml}$. The procedure lasted 6 hours and 27 minutes. B: Upright lateral (left) and anteroposterior (right) full-spine radiographs obtained immediately after surgery, showing adequate placement of spinal instrumentation and spinal alignment. The patient stayed in the hospital for 4 days and was discharged home. C: She did well for a brief period of time, and then returned to the clinic about 3 months after surgery with a catastrophic failure of her spinal instrumentation and proximal junctional kyphosis, as shown in the sagittal CT scan (left) and lateral radiograph (right). D: The patient then underwent a revision and extension of her spinal instrumentation from T-8 to L-3 (anteroposterior [left] and lateral [right] radiographs]). At 31 months after her original surgery, the patient is doing well, with a complete resolution of all preoperative symptoms. E: Sagittal (left) and axial (right) CT scan slices obtained at 12 months after revision surgery, demonstrating a solid bony fusion with no evidence of instrumentation failure. In retrospect, the reason for instrumentation failure after the first surgery is likely because the short-segment spinal construct stopped at the site of the patient's preexisting scoliosis, which was not properly appreciated in the preoperative planning phase. The altered biomechanics of a scoliotic spine overcame the strength of the T12-L2 spinal construct.

recent follow-up was $-5.5^{\circ}$ (range $-35^{\circ}$ to $10^{\circ}$ ), or $5.5^{\circ}$ of lordosis. There was no loss of alignment over time.

MRI studies were available for 2 patients. No patient had new pathology, such as myelomalacia or new or enlarging syringomyelia in the spinal cord. It is difficult to quantitate MRI evidence of spinal cord relaxation.

\section{Discussion}

Traditional untethering in cases of pediatric and adult tethered cord syndrome has shown varied outcomes. ${ }^{5,9,17-19}$,
${ }^{22,28}$ Secondary tethered cord syndrome associated with repair of lipomyelomeningocele and myelomeningocele ${ }^{5,16,23}$ have notably poorer outcomes, likely due to incomplete untethering..$^{18}$ However, complete untethering is technically challenging in this setting, with a high risk of neurological injury and CSF leakage. $9,18,23,30$ Therefore, a window of opportunity exists for a new paradigm - spinal column shortening - for treatment of tethered cord syndrome, with the goal of reduction of spinal cord tension while minimizing surgical complications.

Spinal column shortening has been well described by 
A $\quad$ SRS-22

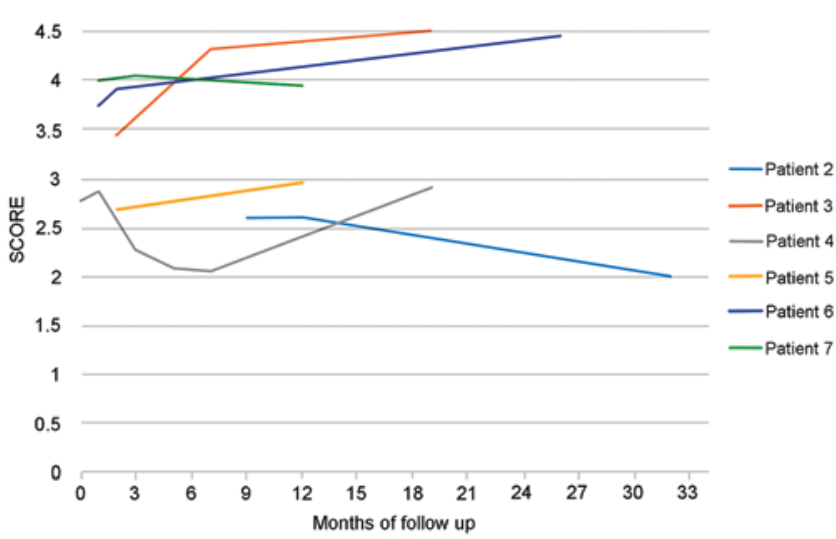

B

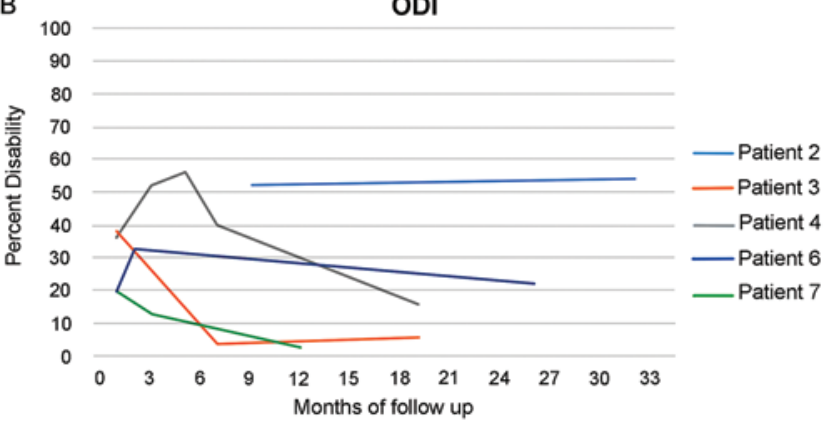

FIG. 2. Line graphs representing the postoperative time course of patients with SRS-22 (A) and ODI (B) data available. Most patient outcomes documented with SRS-22 showed improvement (upward trend line) compared with baseline. Similarly, most patient outcomes documented with ODI showed improvement (downward trend line) compared with baseline. Figure is available in color online only.

many authors in case reports or small case series. Huang et al. ${ }^{15}$ described 21 patients with congenital scoliosis and concurrent tethered cord syndrome who underwent a spinal column shortening procedure (usually resection of a hemivertebra). These patients experienced improved clinical and radiographic outcomes of their tethered cord syndrome and spinal deformity, respectively. The authors also reported a low complication rate of $23.8 \%$, including transient neurological deficit in 1 patient, urinary tract infections in 2 patients, CSF leak in 1 patient, and excessive intraoperative blood loss in 1 patient. They ultimately concluded that spinal column shortening osteotomy for these patients is both safe and efficacious.

In the same vein, Kokubun et al..$^{18}$ reported a series of 8 adult patients with lipomyelomeningocele and secondary tethered cord syndrome (i.e., tethered cord syndrome that develops after the initial repair of the spinal dysraphism). These authors were the first group to describe spinal column shortening as a technique for treatment of recurrent tethered cord syndrome. In that series, they reported that spinal column shortening successfully improves or stabilizes preoperative symptoms, including motor disturbance, muscle atrophy, and bladder dysfunction, for a period of time. They concluded that spinal column shortening-and fusion 1 level above the osteotomy and 1 level below the osteotomy-should be considered a feasible treatment op- tion for patients with tethered cord syndrome associated with spinal lipomas.

Hsieh et al. ${ }^{14}$ reviewed 18 cases of spinal column resection performed for tethered cord syndrome associated with myelomeningocele and lipomyelomeningocele up until 2010. The authors concluded from their review and analysis of the literature that spinal column shortening is a safe and effective alternative to traditional untethering procedures for the treatment of complex tethered cord syndrome. The procedure obviates the risks of an intradural procedure and achieves a reduction in spinal cord tension comparable to extensive untethering of the spinal cord.

Spinal column shortening was frequently performed at L-1 in our series because injury or sacrifice of the T-12 or L-1 nerve roots would result in little to no neurological deficits. Few forms of spinal dysraphism extend rostral to $\mathrm{L}-1$, and the thoracolumbar junction is straightforward to fuse, given a lack of significant kyphosis or lordosis (compared with the thoracic and lumbar spine, respectively) in this region of the spine.

Our technique for spinal column shortening is similar to those already described in the literature..$^{13,14,17,18,25,30}$ One major difference, though, is our use of a PSO rather than a vertebral column resection, as is found in other technical notes. In our overall experience with both types of osteotomy approaches, pedicle subtraction osteotomy confers less instability (as the anterior column is preserved and used as a pivot point), less risk of neurological injury from translation of the spinal column during closure of the osteotomy, decreased blood loss, and decreased operative time, compared with vertebral column resection. Yet PSO still effectively shortens the spinal column. The most significant drawback to PSO is the iatrogenic introduction of lordosis, which may result in clinically significant sagittal imbalance and subsequent back pain.

In our experience, we have found that the risks with spinal column shortening (a "no-touch" technique of the spinal cord) are equivalent to, or even less than, the risks with traditional untethering. The most likely complication of traditional untethering is retethering of the spinal cord from postoperative scar formation; however, this is the most unlikely complication of spinal column shortening. At the last follow-up, none of our patients required reoperation for retethering of the spinal cord after spinal column shortening.

In our study, we estimated the amount of shortening of the spine to be approximately $1.5 \mathrm{~cm}$ at the time of surgery. Previous cadaveric studies 9,30 demonstrated that shortening the spinal column by $12-25 \mathrm{~mm}$ significantly reduces tension on the spinal cord, nerve roots, and filum terminale. This effect was similar to that achieved by traditional untethering, with more than $90 \%$ of the neural elements released. Furthermore, a more limited osteotomy of 12-16 $\mathrm{mm}$ avoided dural buckling, which may cause spinal cord injury. ${ }^{30}$ Hence, our osteotomy target of 1.5 $\mathrm{cm}$ seems appropriate in terms of safety and reduction of mechanical tension in the spinal cord.

There is a school of thought that tethered cord syndrome in adults is due to scarring of the caudal spinal cord, rather than abnormal mechanical traction on the spinal cord..$^{12,29}$ 
TABLE 1. Demographics and clinical and operative data for 7 patients

\begin{tabular}{|c|c|c|c|c|c|c|c|c|c|c|c|}
\hline $\begin{array}{l}\text { Pt } \\
\text { No. }\end{array}$ & $\begin{array}{l}\text { Age } \\
\text { at Op } \\
\text { (yrs), } \\
\text { Sex }\end{array}$ & $\begin{array}{c}\text { Form of } \\
\text { Spinal } \\
\text { Dysraphism }\end{array}$ & Presentation & $\begin{array}{c}\text { No. of } \\
\text { Prior } \\
\text { Untethering } \\
\text { Procedures }\end{array}$ & $\begin{array}{l}\text { Surgical } \\
\text { Procedure }\end{array}$ & $\begin{array}{l}\mathrm{EBL} \\
(\mathrm{ml})\end{array}$ & $\begin{array}{c}\text { Op } \\
\text { Duration } \\
\text { (hrs:mins) }\end{array}$ & $\begin{array}{l}\text { Hospital } \\
\text { Stay } \\
\text { (days) }\end{array}$ & Complications* & $\begin{array}{c}\mathrm{FU} \\
(\mathrm{mos})\end{array}$ & Comments \\
\hline 1 & $8, M$ & MMC & $\begin{array}{l}\text { Holocord } \\
\text { syrinx, hand } \\
\text { weakness }\end{array}$ & 0 & $\begin{array}{l}\text { T12-L2 fusion; } \\
\text { VCR L-1 }\end{array}$ & 600 & $8: 39$ & 5 & None & 37 & $\begin{array}{l}\text { Persistent hand } \\
\text { weakness }\end{array}$ \\
\hline 2 & $19, F$ & LMMC & $\begin{array}{l}\text { Back/leg pain, } \\
\text { B/B dys- } \\
\text { function }\end{array}$ & 3 & $\begin{array}{l}\text { T10-12 fusion; } \\
\text { PSO T-11 }\end{array}$ & 250 & $7: 10$ & 4 & None & 32 & $\begin{array}{l}\text { Worsening back } \\
\text { pain; unrelieved } \\
\text { urinary urgency }\end{array}$ \\
\hline 3 & $30, \mathrm{M}$ & $\begin{array}{l}\text { Transitional } \\
\text { spinal } \\
\text { lipoma }\end{array}$ & $\begin{array}{l}\text { Leg pain, foot } \\
\text { drop }\end{array}$ & 0 & $\begin{array}{l}\text { T12-L2 fusion; } \\
\text { PSO L-1 }\end{array}$ & 750 & $4: 30$ & NA & None & 31 & $\begin{array}{l}\text { Hyperlordosis thora- } \\
\text { columbar junction; } \\
\text { persistent foot } \\
\text { drop; improvement } \\
\text { in sexual function }\end{array}$ \\
\hline 4 & $23, F$ & LMMC & $\begin{array}{l}\text { Back/leg pain, } \\
\text { bladder dys- } \\
\text { function }\end{array}$ & 0 & $\begin{array}{l}\text { T12-L2 fusion; } \\
\text { PSO L-1 }\end{array}$ & 500 & $6: 27$ & 4 & $\begin{array}{l}\text { Catastrophic } \\
\text { failure of in- } \\
\text { strumentation, } \\
\text { PJK after redo } \\
\text { fusion T8-L3 }\end{array}$ & 31 & $\begin{array}{l}\text { Improvement in all } \\
\text { preop symptoms }\end{array}$ \\
\hline 5 & $16, M$ & MMC & $\begin{array}{l}\text { Leg weak- } \\
\text { ness, B/B } \\
\text { dysfunction }\end{array}$ & 3 & $\begin{array}{l}\text { T4-8 fusion; } \\
\text { PSO T-6 }\end{array}$ & 700 & $7: 12$ & 4 & None & 27 & $\begin{array}{l}\text { Improvement in back } \\
\text { pain; T2-pelvis } \\
\text { fusion for severe } \\
\text { scoliosis }\end{array}$ \\
\hline 6 & $10, F$ & MMC & $\begin{array}{l}\text { Back/leg pain, } \\
\text { leg weak- } \\
\text { ness }\end{array}$ & 0 & $\begin{array}{l}\text { T10-L3 fu- } \\
\text { sion; PSO } \\
\text { L-1 }\end{array}$ & 900 & $6: 31$ & 6 & None & 26 & Improvement in pain \\
\hline 7 & $10, F$ & LMMC & $\begin{array}{l}\text { Leg pain, } \mathrm{B} / \mathrm{B} \\
\text { dysfunction }\end{array}$ & 1 & $\begin{array}{l}\text { T12-L2 fusion; } \\
\text { PSO L-1 }\end{array}$ & 350 & $6: 19$ & 5 & None & 32 & $\begin{array}{l}\text { Improvement in pain } \\
\& B / B \text { function }\end{array}$ \\
\hline
\end{tabular}

$\mathrm{B} / \mathrm{B}=$ bowel/bladder; $\mathrm{FU}=$ follow-up; $\mathrm{LMMC}=$ lipomyelomeningocele; $\mathrm{MMC}=$ myelomeningocele; $\mathrm{NA}$ = not available; $\mathrm{PJK}=$ proximal junctional kyphosis; $\mathrm{Pt}=$ patient; $\mathrm{VCR}=$ vertebral column resection .

* New neurological deficit, CSF leak, infection, reoperation, or death.

Scarring around the spinal cord and nerve roots may predispose the spinal cord to abnormal mechanical stress. The abnormal tension of the spinal cord may not be exhibited immediately, and instead it accumulates and increases over time. Certain repetitive activities over the life of an older patient, such as flexing or extending the lower spinal column, can put additional tension on the spinal cord and often worsen tethered cord syndrome. Participation in physical activities, such as strenuous sports, may worsen the signs and symptoms. Abnormal curvature of the spine (scoliosis and exaggerated kyphosis) may also be a potential for symptomatic acceleration. For example, slight flexion of the lower (lumbosacral) spine with a scarred or tethered spinal cord may aggravate back pain by spinal cord stretching. ${ }^{12,29} \mathrm{~A}$ spinal column shortening procedure would be anticipated to similarly reduce spinal cord tension in this patient population.

Most patients (5 of 7) in our series with at least 24 months of follow-up (mean 31 months) demonstrated improvement in preoperative symptoms. This finding is corroborated with our use of standardized health-related quality of life outcomes; most patients showed a trend toward improvement when using SRS-22 and ODI scoring.

The definition of complication in our study included a new neurological deficit, CSF leak, infection, reoperation, or death. Preoperative symptoms that persisted after spinal column shortening were noted but not considered complications. Using this definition of complication, our rate of unexpected outcomes was 14\% (1 of 7 patients); this patient required reoperation for spinal instrumentation failure, as a direct consequence of inappropriate surgical planning and selection of upper and lower instrumented levels. However, this rate compares favorably with other spinal column shortening procedures for tethered cord syndrome. ${ }^{14,15,18}$

Nevertheless, we did have patients who did not report improvement or reported frank worsening after spinal column shortening after brief periods of improvement. The chronicity of spinal cord tension could have caused irreversible changes even after the spinal cord tension had been relieved. In these cases, improvement would not be expected. In our series, the 2 patients who reported worsening after spinal column shortening notably had undergone 3 prior attempts of untethering. A second possible reason for failed treatment could be an inadequate extent of spinal column shortening. Finally, in a growing, skeletally immature child, rapid growth of the nonfused portion of the spinal column may again reestablish tension on the 
spinal cord and symptoms of tethered cord syndrome. In these cases, it may be better to defer spinal column shortening until the child reaches skeletal maturity and stops growing. Moreover, fusion in a skeletally immature child may yield growth retardation (estimated as $1 \mathrm{~mm}$ per vertebral level fused per years of remaining growth) or crankshaft deformity ${ }^{11}$ (unopposed growth of the anterior and middle columns while the posterior column is tethered by the fusion).

A significant limitation of our study is the wide age discrepancy (range 8-30 years old) This heterogeneity may make it difficult to draw generalizable conclusions.

\section{Conclusions}

The traditional, or gold-standard, treatment of tethered cord syndrome associated with myelomeningocele, spinal lipoma, and lipomyelomeningocele consists of a direct untethering of the spinal cord. The outcomes of this surgical approach are less than favorable; rates of symptomatic retethering are high, and, with each subsequent untethering procedure, the risks of neurological injury, CSF leakage, and wound infection increase, while the ability to effectively untether the spinal cord decreases. Spinal column shortening appears to be a safe and efficacious option for the treatment of tethered cord syndrome both in our small series of pediatric and young adult patients, as well as in other series of patients treated in this manner in our review of the literature. However, many questions remain unanswered, such as the inconsistency and durability of our outcomes, indications and patient selection for spinal column shortening, as well as timing of surgery, especially in a growing skeletally immature child. Further studies are necessary to address these concerns.

\section{References}

1. Asher M, Min Lai S, Burton D, Manna B: Discrimination validity of the Scoliosis Research Society-22 patient questionnaire: relationship to idiopathic scoliosis curve pattern and curve size. Spine (Phila Pa 1976) 28:74-78, 2003

2. Asher M, Min Lai S, Burton D, Manna B: The reliability and concurrent validity of the Scoliosis Research Society-22 patient questionnaire for idiopathic scoliosis. Spine (Phila Pa 1976) 28:63-69, 2003

3. Asher M, Min Lai S, Burton D, Manna B: Scoliosis Research Society-22 patient questionnaire: responsiveness to change associated with surgical treatment. Spine (Phila Pa 1976) 28:70-73, 2003

4. Chapman PH: Congenital intraspinal lipomas: anatomic considerations and surgical treatment. Childs Brain 9:37-47, 1982

5. Cochrane DD: Cord untethering for lipomyelomeningocele: expectation after surgery. Neurosurg Focus 23(2):E9, 2007

6. Copay AG, Glassman SD, Subach BR, Berven S, Schuler TC, Carreon LY: Minimum clinically important difference in lumbar spine surgery patients: a choice of methods using the Oswestry Disability Index, Medical Outcomes Study questionnaire Short Form 36, and pain scales. Spine J 8:968-974, 2008

7. Crawford CH III, Glassman SD, Bridwell KH, Berven SH, Carreon LY: The minimum clinically important difference in SRS-22R total score, appearance, activity and pain domains after surgical treatment of adult spinal deformity. Spine (Phila Pa 1976) 40:377-381, 2015
8. Fairbank JC, Couper J, Davies JB, O'Brien JP: The Oswestry low back pain disability questionnaire. Physiotherapy 66:271-273, 1980

9. Grande AW, Maher PC, Morgan CJ, Choutka O, Ling BC, Raderstorf TC, et al: Vertebral column subtraction osteotomy for recurrent tethered cord syndrome in adults: a cadaveric study. J Neurosurg Spine 4:478-484, 2006

10. Gressot LV, Patel AJ, Hwang SW, Fulkerson DH, Jea A: RhBMP-2 for L5-S1 arthrodesis in long fusions to the pelvis for neuromuscular spinal deformity in the pediatric age group: analysis of 11 patients. Childs Nerv Syst 30:249-255, 2014

11. Herring JA: Anterior spinal surgery, in Weinstein SL (ed): Pediatric Spine Surgery, ed 2. Philadelphia: Lippincott Williams \& Wilkins, 2001

12. Hertzler DA II, DePowell JJ, Stevenson CB, Mangano FT: Tethered cord syndrome: a review of the literature from embryology to adult presentation. Neurosurg Focus 29(1):E1, 2010

13. Hsieh PC, Ondra SL, Grande AW, O'Shaughnessy BA, Bierbrauer K, Crone KR, et al: Posterior vertebral column subtraction osteotomy: a novel surgical approach for the treatment of multiple recurrences of tethered cord syndrome. J Neurosurg Spine 10:278-286, 2009

14. Hsieh PC, Stapleton CJ, Moldavskiy P, Koski TR, Ondra SL, Gokaslan ZL, et al: Posterior vertebral column subtraction osteotomy for the treatment of tethered cord syndrome: review of the literature and clinical outcomes of all cases reported to date. Neurosurg Focus 29(1):E6, 2010

15. Huang JH, Yang WZ, Shen C, Chang MS, Li H, Luo ZJ, et al: Surgical treatment of congenital scoliosis associated with tethered cord by thoracic spine-shortening osteotomy without cord detethering. Spine (Phila Pa 1976) 40:E1103-E1109, 2015

16. Kanev PM, Bierbrauer KS: Reflections on the natural history of lipomyelomeningocele. Pediatr Neurosurg 22:137-140, 1995

17. Kanno H, Aizawa T, Ozawa H, Hoshikawa T, Itoi E, Kokubun S: Spine-shortening vertebral osteotomy in a patient with tethered cord syndrome and a vertebral fracture. Case report. J Neurosurg Spine 9:62-66, 2008

18. Kokubun S, Ozawa H, Aizawa T, Ly NM, Tanaka Y: Spineshortening osteotomy for patients with tethered cord syndrome caused by lipomyelomeningocele. J Neurosurg Spine 15:21-27, 2011

19. Koyanagi I, Iwasaki Y, Hida K, Abe H, Isu T, Akino M: Surgical treatment supposed natural history of the tethered cord with occult spinal dysraphism. Childs Nerv Syst 13:268-274, 1997

20. Kulkarni AV, Pierre-Kahn A, Zerah M: Conservative management of asymptomatic spinal lipomas of the conus. Neurosurgery 54:868-875, 2004

21. Lam SK, Sayama C, Harris DA, Briceño V, Luerssen TG, Jea A: Nationwide practice patterns in the use of recombinant human bone morphogenetic protein-2 in pediatric spine surgery as a function of patient-, hospital-, and procedure-related factors. J Neurosurg Pediatr 14:476-485, 2014

22. Lapsiwala SB, Iskandar BJ: The tethered cord syndrome in adults with spina bifida occulta. Neurol Res 26:735-740, 2004

23. Lee GY, Paradiso G, Tator CH, Gentili F, Massicotte EM, Fehlings MG: Surgical management of tethered cord syndrome in adults: indications, techniques, and long-term outcomes in 60 patients. J Neurosurg Spine 4:123-131, 2006

24. Maher CO, Goumnerova L, Madsen JR, Proctor M, Scott RM: Outcome following multiple repeated spinal cord untethering operations. J Neurosurg 106 (6 Suppl):434-438, 2007

25. Miyakoshi N, Abe E, Suzuki T, Kido T, Chiba M, Shimada Y: Spine-shortening vertebral osteotomy for tethered cord 
syndrome: report of three cases. Spine (Phila Pa 1976) 34:E823-E825, 2009

26. Pang D, Wilberger JE Jr: Tethered cord syndrome in adults. J Neurosurg 57:32-47, 1982

27. Phuong LK, Schoeberl KA, Raffel C: Natural history of tethered cord in patients with meningomyelocele. Neurosurgery 50:989-995, 2002

28. Rajpal S, Tubbs RS, George T, Oakes WJ, Fuchs HE, Hadley $\mathrm{MN}$, et al: Tethered cord due to spina bifida occulta presenting in adulthood: a tricenter review of 61 patients. $\mathbf{J}$ Neurosurg Spine 6:210-215, 2007

29. Romagna A, Suchorska B, Schwartz C, Tonn JC, Zausinger $\mathrm{S}$ : Detethering of a congenital tethered cord in adult patients: an outcome analysis. Acta Neurochir (Wien) 155:793-800, 2013

30. Safain MG, Burke SM, Riesenburger RI, Zerris V, Hwang SW: The effect of spinal osteotomies on spinal cord tension and dural buckling: a cadaveric study. J Neurosurg Spine 23:120-127, 2015

31. Sayama C, Hadley C, Monaco GN, Sen A, Brayton A, Briceño V, et al: The efficacy of routine use of recombinant human bone morphogenetic protein-2 in occipitocervical and atlantoaxial fusions of the pediatric spine: a minimum of 12 months' follow-up with computed tomography. J Neurosurg Pediatr 16:14-20, 2015

32. Sayama C, Willsey M, Chintagumpala M, Brayton A,
Briceño V, Ryan SL, et al: Routine use of recombinant human bone morphogenetic protein-2 in posterior fusions of the pediatric spine and incidence of cancer. J Neurosurg Pediatr 16:4-13, 2015

33. Yamada S, Zinke DE, Sanders D: Pathophysiology of "tethered cord syndrome.” J Neurosurg 54:494-503, 1981

\section{Disclosures}

The authors report no conflict of interest concerning the materials or methods used in this study or the findings specified in this paper.

\section{Author Contributions}

Conception and design: Jea. Acquisition of data: all authors. Analysis and interpretation of data: all authors. Drafting the article: Jea, Aldave. Critically revising the article: Jea, Aldave. Reviewed submitted version of manuscript: Jea, Aldave. Study supervision: Jea.

\section{Correspondence}

Andrew Jea, Section of Pediatric Neurosurgery, Riley Hospital for Children, 705 Riley Hospital Dr. \#1134, Indianapolis, IN 46202. email: ajea@goodmancampbell.com. 